\title{
Regional Assessment of the Virtual Water of Sheep and Goats in Arid Areas
}

\author{
Ke Zhang ${ }^{1, \dagger}$, Chao $\mathrm{Li}^{1, \dagger}$, Wen Bao ${ }^{1}$, Mengmeng Guo ${ }^{1}$, Qi Zhang ${ }^{1}$, Yuxin Yang ${ }^{1}$, Qifang Kou ${ }^{2}$, \\ Wenrui Gao ${ }^{3}$, Xiaolong Wang ${ }^{1}$, Zhaoxia Yang ${ }^{1, *}$, Yulin Chen ${ }^{1, *}$ \\ ${ }^{1}$ College of Animal Science and Technology, Northwest A\&F University, Yangling, China \\ ${ }^{2}$ Ningxia Tan Sheep Farm, Hongsibu, China \\ ${ }^{3}$ Shanbei Cashmere Goats Farm, Hengshan, China
}

Email address:

chenyulin@nwafu.edu.cn (Yulin Chen),yangzhx72@163.com (Zhaoxia Yang)

*Corresponding author

$\dagger$ Ke Zhang and Chao Li are co-first authors.

\section{To cite this article:}

Ke Zhang, Chao Li, Wen Bao, Mengmeng Guo, Qi Zhang, Yuxin Yang, Qifang Kou, Wenrui Gao, Xiaolong Wang, Zhaoxia Yang, Yulin Chen. Regional Assessment of the Virtual Water of Sheep and Goats in Arid Areas. Animal and Veterinary Sciences. Vol. 6, No. 4, 2018 , pp. 58-66. doi: $10.11648 /$ j.avs.20180604.12

Received: August 13, 2018; Accepted: August 29, 2018; Published: October 13, 2018

\begin{abstract}
The increased consumption of livestock products is likely to put further pressure on the world's freshwater resources, an agricultural virtual water strategy will alleviate the water resources pressure of livestock husbandry, especially in arid areas. The research on the virtual water requirement of living animals is still blank in China. Most of the researches on the virtual water of animal products in China adopt foreign data and there is some error with the actual situation in China. In this study, the virtual water requirements of sheep and goats $(n=80)$ in North China were evaluated and validated. Factors that affect animals' virtual water requirements and the water supply for sheep and goat management were analyzed. We found that the virtual water productivity in sheep at five growth stages (40-day-old [D40], 6-month [M6], 12-month-old [M12], 24-month-old [M24], and 36-month-old [M36]) was lower than that in goats. The amount of virtual water requirements was $496.07 \mathrm{~m}^{3}$ from birth to M36 in sheep and was $217.14 \mathrm{~m}^{3}$ in goats. The water consumes were estimated to be $9019.4 \mathrm{~m}^{3} / \mathrm{t}$ in sheep and $4825.3 \mathrm{~m}^{3} / \mathrm{t}$ in goats. The virtual water requirement for feed accounted for more than $99 \%$ of the total water consumption. Daily water consumption in rams is larger than that in ewes. We found that the crop type and yield, the proportion of high water consumption feed raw material in complete diet pellets, as well as the flock structure are the three major factors influencing virtual water demand in animals. Our results provided strategies to reduce water consumption in animal husbandry industries in arid areas, and further show that the crop import trade strategies can be used to increase the import of high water-consuming crops, instead of the virtual water consumption of the sheep and goat industry output, thereby alleviating the pressure on local water resources.
\end{abstract}

Keywords: Virtual Water, Water Resource, Goat, Sheep, Animal Husbandry

\section{Introduction}

Freshwater is a renewable resource, but the world's total groundwater supplies are declining with population growth, with the most common water losses occurring in Asia and North America [1]. China is a country that experiences severe water scarcity and a series of water diversion projects have been carried out in China to improve water resource availability. However, the use of groundwater and surface water for industrial and agricultural purposes has led to environmental degradation, which has made the problem of water supply and demand even more severe. At present, the scale of desertification in China is 1.74 million $\mathrm{km}^{2}$ and more than $90 \%$ of the native grassland has been degraded, with a total soil erosion area of $356 \mathrm{~km}^{2}$ [2].

The concept of virtual water was first proposed in 1993 by Professor Allan of King's College London, which led to the field of virtual water research [3, 4]. Later, he proposed the 
concept of virtual water trade [5]. Virtual water is defined as the sum of the amount of water used to produce goods and services. To date, research on virtual water has focused on agricultural and livestock products. These products consume large amounts of water in processing primary raw materials. This has become a widespread concern. Previous studies analyzed of the agricultural water footprint in China based on the LMDI (log-mean Divisia index) method, they accounted for the Chinese agricultural water footprint from 1990 to 2009 based on bottom up approach, the results reveal that the Chinese agricultural water footprint has risen from the 94.1 $\mathrm{Gm}^{3}$ in 1990 to $141 \mathrm{Gm}^{3}$ in 2009 [6]. Previous study has analyzed the water-footprint of crop production, import, and export on a country level, using Israel as a case study, comparing data from two high-resolution local databases and two global datasets [7]. And some study determines the volume of virtual water contained in agricultural and livestock products imported/exported by Brazil from 1997 to 2012, and to define the water self-sufficiency index of agricultural and livestock products in Brazil [8]. In China, previous study investigated the virtual water flows in the international trade of agricultural products, the result found that the trend that China exported virtual water per year was on the decline while the imported was on a rising trend. Virtual water trade of China was highly concentrated [9]. Based on this body of research, we found that the study of virtual water has also changed the traditional research viewpoint of physical water, instead of trade flows with the water resources. Since the advent of the concept of virtual water, its research has been widely recognized and new results are emerging that are closely integrated with management practices that could optimize water conservation policies and adjust industrial practices. Results have even successfully resolved some regional disputes due to lack of water resources $[10,11]$. But virtual water theory lacks a detailed data system. Quantitative research on virtual water for tertiary industries has no clear consensus, and there is a gap in the quantitative research on gray virtual water. In China, research on virtual water is still in its infancy. In addition to this, there is a lack of research on the relationship between international trade and other regions. From a strategic point of view, there is a lack of evidence for the actual needs and arguments on the maturity of China's regional virtual water trade conditions.

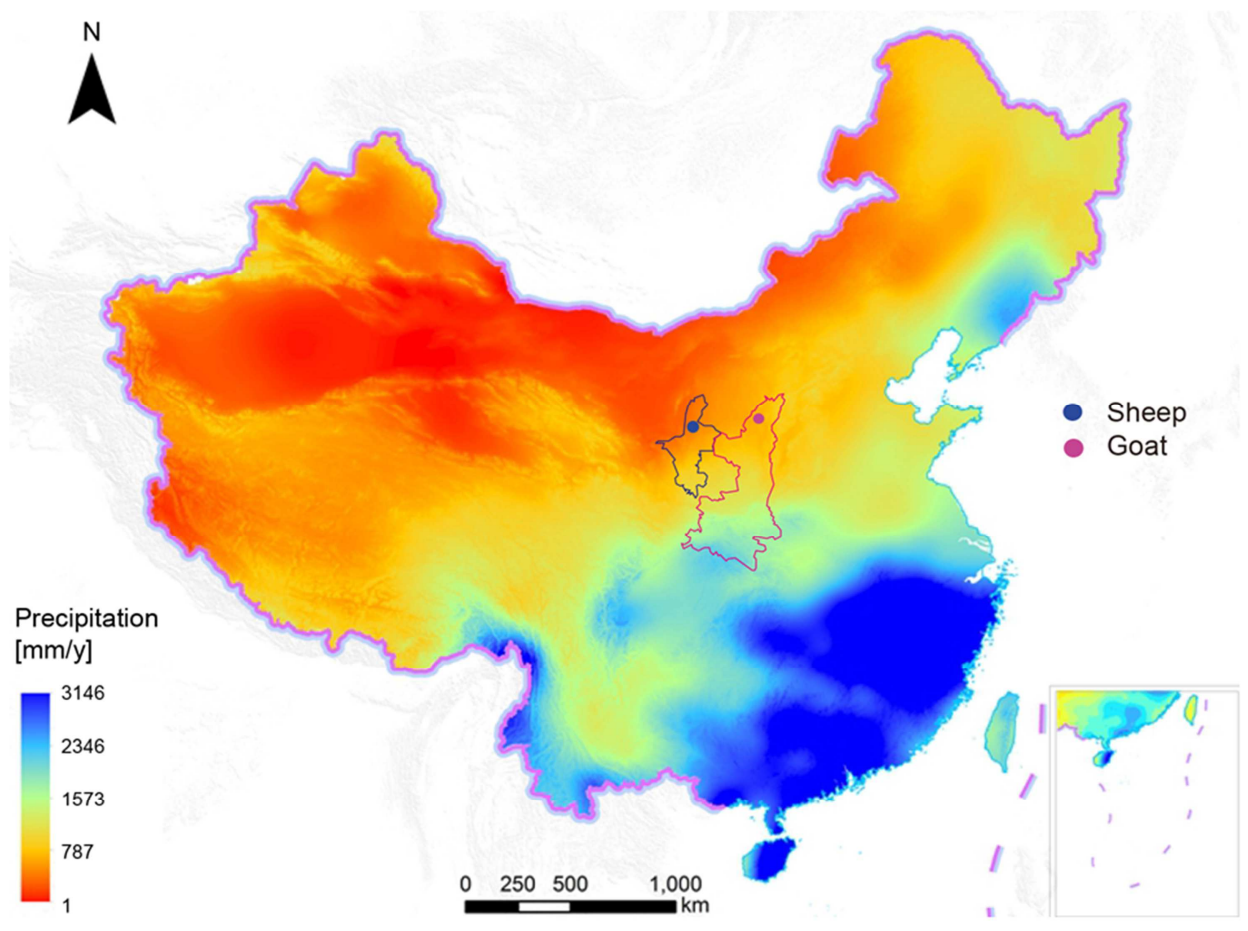

Figure 1. Annual rainfall in northern China and the distribution of sheep and goats.

Shaanxi Province and Ningxia Province are located in Northwest China (Figure.1). The spatial distribution of water resources in this region is uneven and there is a sharp contrast between water supply and demand. The Cashmere goat is a unique local breed in Shaanxi Province because of its high Cashmere yield and excellent quality meat. As a result, it has resulted in impressive economic benefits for local residents. Therefore, the proportion of this breed of goat has gradually increased over the years in Shaanxi Province. Ningxia is the center for Tan-sheep production as the local demand for fur and mutton has grown. Tan sheep farming has also increased with the change of time. Sheep breeding requires a significant amount of water resources, which have been under tremendous pressure with increasing goat and sheep production in Shaanxi and Ningxia. It is necessary to explore the factors of influence on virtual water demand and its effect on the arid areas for the sheep and goat industry. To improve water productivity for this industry in arid areas, a virtual water strategy should be implemented. In this study, the virtual water requirements of goats and sheep $(n=80)$ 
breeds were evaluated in order to obtain the main factors of influence for the virtual water demand of the sheep and goat industry, and to provide a data foundation for a virtual water strategy in arid areas.

\section{Materials and Methods}

\subsection{Animal Feeding and Management}

The experimental animals used in the present study included 40 goats and 40 sheep. The females were fed a different diet during gestation (Table A1/A2). Sheep and goats that shared the same age and body weight were divided into five age groups (40-day-old [D40], 6-month [M6], 12-month-old [M12], 24-month-old [M24], and 36-month-old [M36], $\mathrm{n}=8$ for each group, 4 males and 4 females each group). The sheep and goats were randomly selected from animals being raised at the experimental stations of the Ningxia Tan Sheep Farm and the Shaanbei
Cashmere Goat Farm. The experiment lasted for 35 days. Each group of sheep and goats were evaluated for 15 days prior to feeding (10 days for the D40 group), 5 days of pre-feeding, and 20 days of feeding (15 days for the D40 group). The specific feeding steps of this experiment are shown in Table 1.

The pre-feeding test was carried out in the sheep pen and the feeding period was carried out in a metabolic cage (the D40 group was tested in a sheep pen). During the trial period, the sheep were allowed to freely drink water and consume feed. They were fed at 8:00 and 18:00 daily and then fasted to weigh. The lambs were free to feed from their mother's milk until 30 days of age. The lamb was free to breastfeed before 30 days. In addition to milk, the lambs were fed complete diet pellets at 30 60 days and weaned at 60 days. The remaining sheep and goats were fed with the complete diet pellets.

Table 1. The specific feeding steps for sheep and goats.

\begin{tabular}{lllll}
\hline Time/days & D40 & M6 & M12 & M24 \\
\hline $1 \sim 5$ & Pre-feeding & & & \\
$6 \sim 10$ & Pre-feeding & Pre-feeding & Pre-feeding & \\
$11 \sim 15$ & Pre-feeding & Pre-feeding & Pre-feeding & Pre-feeding \\
$16 \sim 20$ & Feeding & Pre-feeding & Pre-feeding & Pre-feeding \\
$21 \sim 25$ & & Feeding & Feeding & Pre-feeding \\
$26 \sim 30$ & & & & Feeding \\
$31 \sim 35$ & & & & Pre-feeding \\
\hline
\end{tabular}

\subsection{Calculation of the Virtual Water Content for Live Animals}

Since the virtual water content of the feed raw materials is limited by the region, this experiment assumes that the feed raw materials for sheep and goats are locally produced. The experiment data is mainly composed of two parts: feed raw material related data of sheep and goats, feeding and management related data of sheep and goat, feed raw material related data mainly include climate parameters of feed crop, crop coefficient and crop yield. The climatic parameters include the highest temperature and the lowest temperature, the average relative humidity, the average daily sunshine hours, the monthly mean wind speed and the net radiation in the year of 2014 at Shaanxi and Ningxia. The date of climatic parameters and crop coefficient come from http://www.chinayearbook.com/tongji/item/1/195636.html, http://www.shaanxitj.gov.cn/upload/2016/tongjinianj/2015/in dexch.htm, http://data.cma.cn/, http://www.fao.org/statistics/databases/zh/, the date of feed crop yield and acreage come from http://www.stats.gov.cn/tjsj/ndsj/2015/indexch.htm. The CROPWAT model developed by the United Nations Food and Agriculture Organization (FAO) was used to calculate the crop water requirements. The FAO-recommended software CROPWAT8.0 software was used to obtain reference crop evapotranspiration, which was combined with different crop yields to obtain different feed crop water requirements. The virtual water content of the feed composition was determined by the value proportion of different feeds.

\subsection{The Three Components of the Virtual Water Content for a Live Animal}

In this study, body weight, feed intake, water consumption, and feed water requirements at different stages were obtained by averaging the maximum and minimum values of all the data from a particular stage. There are three components to the virtual water content for a live animal.

$$
\mathrm{VWC} \text { a }[\mathrm{e}, \mathrm{a}]=\mathrm{VWC}_{\text {feed }}[\mathrm{e}, \mathrm{a}]+\mathrm{VWC}_{\text {drink }}[\mathrm{e}, \mathrm{a}]+\mathrm{VWC}_{\text {service }}[\mathrm{e}, \mathrm{a}]
$$

Where VWC a $[\mathrm{e}, \mathrm{a}]$ represents the virtual water content for an animal in exporting country e expressed in cubic meters of water per ton of live animal. $\mathrm{VWC}_{\text {feed, }}, \mathrm{VWC}_{\text {drink }}$ and $\mathrm{VWC}_{\text {service }}$ are the respective virtual water contents from feeding, drinking, and servicing.

\subsection{Virtual Water Content from Feed Consumed}

The following calculation method is used for reference from this paper [12]. The virtual water content for an animal from the feed consumed has two parts. The first is the actual water that is required to prepare the feed mix and the second is the virtual water incorporated into the various feed 
ingredients. The virtual water content from feeding an animal

throughout its total lifespan is calculated as follows:

$$
\mathrm{VWC}_{\text {feed }}[\mathrm{e}, \mathrm{a}]=\int_{\text {birth }}^{\text {slaughter }}\left\{q_{\text {mixing }}[e, a]+\sum_{c=1}^{n_{c}} S W D[e, c] \times C[e, a, c]\right\} d t
$$

Here $V W C_{\text {feed }}[\mathrm{e}, \mathrm{a}]$ represents the total amount of individual feed virtual water $\left(\mathrm{m}^{3}\right)$. The variable $\mathrm{q}$ mixing $[\mathrm{e}, \mathrm{a}]$ represents the volume of water required for mixing the feed for an animal in country $e\left(\mathrm{~m}^{3} /\right.$ day). $C[e, a, c]$ is the quantity of feed crop $c$ consumed by an animal in country $e(\mathrm{~kg} / \mathrm{d})$. $S W D[e, c]$ is the specific water demand of crop $c$ in exporting country $e\left(\mathrm{~m}^{3} / \mathrm{kg}\right)$.

The virtual water content of the raw feed material is the ratio of the water demand per unit area of raw materials to the total raw materials per unit area;

$$
\operatorname{SWD}[\mathrm{e}, \mathrm{c}]=\frac{C W R[e, c]}{C Y[e, c]}
$$

Here $C W R[e, c]$ represents the crop water requirement for crop $c$ in country $e\left(\mathrm{~m}^{3} / \mathrm{hm}^{2}\right)$ and $C Y[e, c]$ is the crop yield $\left(\mathrm{t} / \mathrm{hm}^{2}\right)$.

The virtual water content for drinking water is calculated

$$
\mathrm{VWC}_{\text {drink }}[\mathrm{e}, \mathrm{a}]=\int_{\text {birth }}^{\text {slaughter }} \mathrm{q}_{\mathrm{d}}[\mathrm{e}, \mathrm{a}] \mathrm{dt}
$$

Where $\mathrm{q}_{\mathrm{d}}[\mathrm{e}, \mathrm{a}]$ is the daily drinking water requirement of an animal in exporting country e $\left(\mathrm{m}^{3} /\right.$ day).

The virtual water content for service water is calculated as:

$$
\mathrm{VWC}_{\text {service }}[\mathrm{e}, \mathrm{a}]=\int_{\text {birth }}^{\text {slaughter }} \mathrm{q}_{\text {serv }}[\mathrm{e}, \mathrm{a}] \mathrm{dt}
$$

Where $V W C_{\text {service }}[e, a]$ represents the virtual water content of an animal in exporting country $e$ and is expressed in cubic meters of water per ton of live animal. q service $[e, a]$ is the daily service water requirement (m3/day) of an animal in exporting country e. In this experiment, we have been calculated for a long time, virtual water content is $2.28 \mathrm{~m}^{3} / \mathrm{d}$ from servicing water supply of sheep and goats from D40 to M36.

The particular analysis process is presented in Figure 2. as:

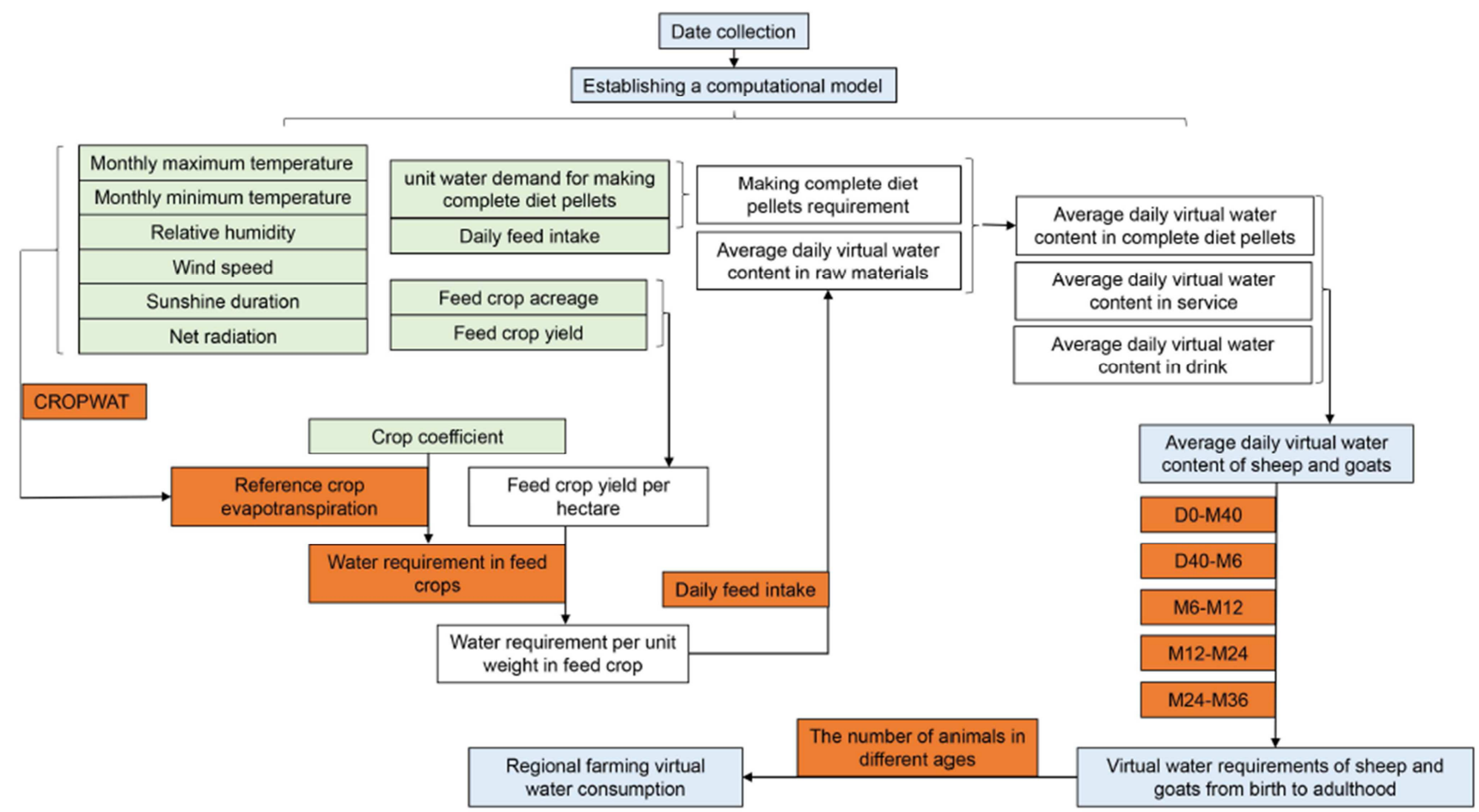

Figure 2. Flow chart on the calculation of sheep and goat farming water consumption. Including the relevant data collation, meteorological data collection, the establishment of the calculation model, sheep and goat feeding and management, sheep and goat breeding water consumption.

\section{Results}

\subsection{The Feed Raw Material Virtual Water Content for Sheep and Goats}

The virtual water content was compared for the same feed crops in Shaanxi and Ningxia Provinces. The results found that the virtual water content of the same feed crop was higher in Ningxia than that Shaanxi Province (Figure 3A).
The virtual water content for a feed crop was determined by crop yield per unit area and water demand. Ningxia has a drier climate than Shaanxi. Water evaporation and plant transpiration are therefore higher, causing the local crops in Ningxia to have a higher water demand than Shaanxi. Different feed crop varieties also had different yield per unit area. These factors all led to a difference in the virtual water content for the same feed crop in Ningxia and Shaanxi Provinces (Figure 3A). 
A

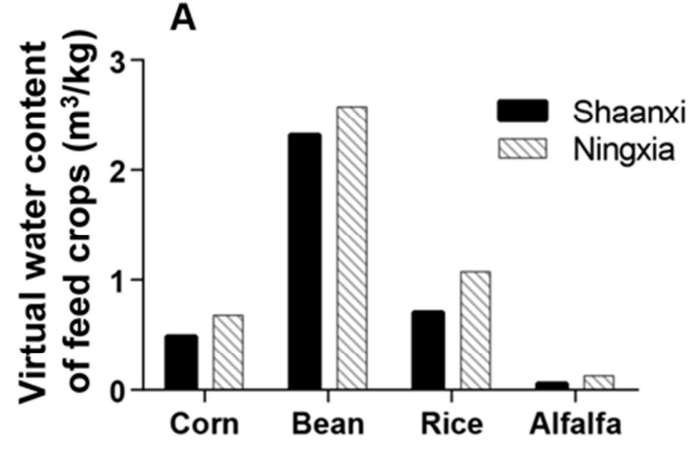

B

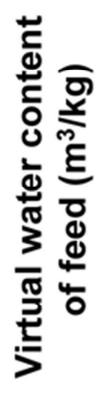

\section{Feed crop}

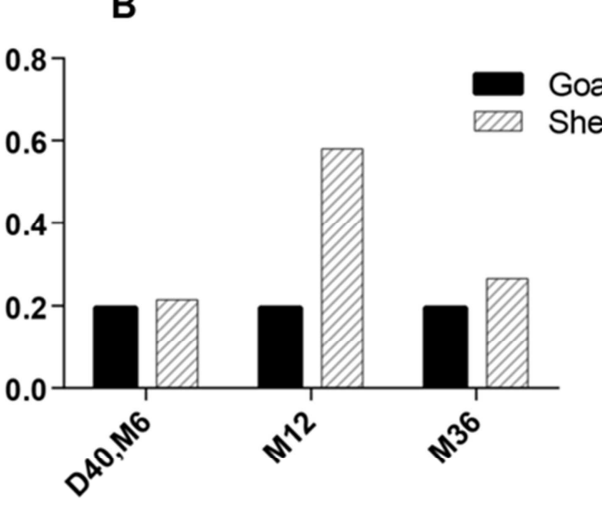

Age

Figure 3. Goat and sheep virtual water related data. (A) Virtual water content of feed crops in Shaanxi and Ningxia ( $\left.\mathrm{m}^{3} / \mathrm{kg}\right)$. (B) Virtual water content of sheep and goat feed $\left(\mathrm{m}^{3} / \mathrm{kg}\right)$.

\subsection{The Complete Diet Pellets Virtual Water Content for Sheep and Goats}

The virtual water content of complete diet pellets was calculated according to the virtual water content of different feed crops and the percent of feed raw material in different ages group. The results showed that the complete diet pellets virtual water content is highest of sheep at 12 months of ages (Figure 3B), the reason is that the complete diet pellets have the highest proportion of cereals. the feed raw material virtual water content and percent is different in the complete diet pellets, which makes the different levels of complete diet pellets virtual water content at difference age group. The complete diet pellets virtual water content for goats is the same at the at all ages group (Figure 3B).

\subsection{The Composition of Virtual Water Requirements for Sheep and Goats}

In this study, the virtual daily water requirements of sheep and goats for 40 days, 6 months, 12 months, 24 months, and
36 months of age were calculated. Measurements of the following variables were collected: feed virtual water requirement, water intake, and feed mix water demand and service water consumption (Table 2-3). Results for all variables in the 40-day-old (D40) age group were much lower than those of the other stages because the main feed source needed to sustain growth was breast milk. Feed intake and water consumption were far less than in the other age groups. Daily water intake increased with age. Service water mainly included feed tank cleaning and medicated baths, the latter of which occurs in the spring and autumn each year, statistics on the total water consumption of medicated baths, and the average distribution to each sheep and goat. Therefore, the daily service water consumption is the daily feed tank cleaning water consumption and the average bath water consumption. The amount of water that was mixed into the feed was the amount of water added to make the pellets, which varied depending on feed ingredients for different age groups.

Table 2. The composition of daily virtual water requirements for goats.

\begin{tabular}{|c|c|c|c|c|c|c|c|c|}
\hline \multicolumn{2}{|c|}{ Virtual water requirement $\left(\mathrm{m}^{3} / \mathrm{d}\right)$} & \multirow{2}{*}{$\begin{array}{l}\text { D40 } \\
1.72^{\mathrm{a}}\end{array}$} & \multirow{2}{*}{$\begin{array}{l}\text { M6 } \\
10.05^{\mathrm{b}}\end{array}$} & \multirow{2}{*}{$\begin{array}{l}\text { M12 } \\
20.80^{\text {c }}\end{array}$} & \multirow{2}{*}{$\begin{array}{l}\text { M24 } \\
28.20^{\mathrm{d}}\end{array}$} & \multirow{2}{*}{$\begin{array}{l}\text { M36 } \\
30.70^{\mathrm{e}}\end{array}$} & \multirow{2}{*}{$\begin{array}{l}\text { SEM } \\
2.52\end{array}$} & \multirow{2}{*}{$\begin{array}{l}\boldsymbol{P} \text {-value } \\
<0.001\end{array}$} \\
\hline $\operatorname{Diet}\left(10^{-2}\right)$ & $\sigma^{2}$ & & & & & & & \\
\hline & 우 & $1.50^{\mathrm{a}}$ & $7.50^{\mathrm{b}}$ & $17.70^{\mathrm{c}}$ & $22.70^{\mathrm{d}}$ & $25.90^{\mathrm{e}}$ & 2.11 & $<0.001$ \\
\hline \multirow[t]{2}{*}{ Feed mixed $\left(10^{-5}\right)$} & $\hat{0}$ & $0.66^{\mathrm{a}}$ & $3.98^{\mathrm{b}}$ & $8.90^{\mathrm{c}}$ & $13.23^{\mathrm{d}}$ & $14.39^{\mathrm{d}}$ & 1.21 & $<0.001$ \\
\hline & o & $0.59^{\mathrm{a}}$ & $2.94^{\mathrm{b}}$ & $7.59^{\mathrm{c}}$ & $10.64^{\mathrm{d}}$ & $12.18^{\mathrm{e}}$ & 1.01 & $<0.001$ \\
\hline \multirow[t]{2}{*}{ Drink $\left(10^{-3}\right)$} & $\hat{0}$ & $0.31^{\mathrm{a}}$ & $0.83^{\mathrm{b}}$ & $1.08^{\mathrm{c}}$ & $1.77^{\mathrm{d}}$ & $2.32^{\mathrm{e}}$ & 0.16 & $<0.001$ \\
\hline & o & $0.23^{\mathrm{a}}$ & $0.83^{\mathrm{b}}$ & $0.85^{\mathrm{b}}$ & $1.38^{\mathrm{c}}$ & $1.67^{\mathrm{d}}$ & 0.11 & $<0.001$ \\
\hline Feed $\left(10^{-2}\right)$ & $\hat{\sigma}$ & $1.71^{\mathrm{a}}$ & $10.52^{\mathrm{b}}$ & $21.01^{\mathrm{c}}$ & $28.45^{\mathrm{d}}$ & $30.96^{\mathrm{e}}$ & 2.53 & $<0.001$ \\
\hline
\end{tabular}

a, b, c, d, e Values within a row with different superscripts differ significantly a $P<0.01$.

In this experiment, the daily virtual water requirements for goats were measured at 40 days, 6 months, 12 months, 24 months, and 36 months, the daily virtual water requirement of goats for the 40 days was $0.016 \mathrm{~m}^{3}$, for the 6 months period it was $0.092 \mathrm{~m}^{3}$; the 12 mouths result was $0.195 \mathrm{~m}^{3}$; the 24 -month result was $0.257 \mathrm{~m}^{3}$; and the 36 -month result was $0.286 \mathrm{~m}^{3}$ (Figure 4A). The total water requirement for goats from birth to 36 months of age was $217.14 \mathrm{~m}^{3}$. At this time the goats weight about $45 \mathrm{~kg}$, so the virtual water content about $4825.3 \mathrm{~m}^{3} / \mathrm{t}$ for goats.

The same estimation method that was used above for goats was used for sheep. The virtual water requirement for the 40 days was $0.054 \mathrm{~m}^{3}$, for the 6 -month period it was $0.385 \mathrm{~m}^{3}$; the 12 -mouth result was $0.835 \mathrm{~m}^{3}$; the 24 -month result was $0.455 \mathrm{~m}^{3}$; and the $36-$ month result was $0.484 \mathrm{~m}^{3}$ (Figure 4B). The total virtual water requirement was $496.07 \mathrm{~m}^{3}$ for a 
sheep raised to 36 months of age. At this time the sheep weight about $55 \mathrm{~kg}$, so the virtual water content about 9019 $\mathrm{m}^{3} / \mathrm{t}$ for sheep. The information generated from both of these experiments can be used to calculate different types of livestock water consumption in different areas of the world.

Table 3. The composition of virtual water requirements for sheep.

\begin{tabular}{|c|c|c|c|c|c|c|c|c|}
\hline \multicolumn{2}{|c|}{ Virtual water requirement $\left(\mathrm{m}^{3} / \mathrm{d}\right)$} & \multirow{2}{*}{$\begin{array}{l}\text { D40 } \\
5.20^{\mathrm{a}}\end{array}$} & \multirow{2}{*}{$\frac{\text { M6 }}{40.80^{\mathrm{b}}}$} & \multirow{2}{*}{$\frac{\text { M12 }}{88.35^{\mathrm{c}}}$} & \multirow{2}{*}{$\frac{\text { M24 }}{46.90^{d}}$} & \multirow{2}{*}{$\frac{\text { M36 }}{49.50^{d}}$} & \multirow{2}{*}{$\frac{\text { SEM }}{6.08}$} & \multirow{2}{*}{$\frac{\boldsymbol{P} \text {-value }}{<0.001}$} \\
\hline Diet $\left(10^{-2}\right)$ & $\hat{0}$ & & & & & & & \\
\hline & 우 & $5.00^{\mathrm{a}}$ & $35.40^{\mathrm{b}}$ & $77.00^{\mathrm{c}}$ & $43.20^{\mathrm{d}}$ & $46.50^{\mathrm{d}}$ & 5.29 & $<0.001$ \\
\hline Feed mixed $\left(10^{-5}\right)$ & $\hat{0}$ & $1.07^{\mathrm{a}}$ & $5.55^{\mathrm{b}}$ & $7.98^{\mathrm{c}}$ & $9.47^{\mathrm{d}}$ & $10.20^{\mathrm{d}}$ & 0.76 & $<0.001$ \\
\hline \multirow[t]{2}{*}{ Drink $\left(10^{-3}\right)$} & $\hat{0}$ & $1.46^{\mathrm{a}}$ & $1.46^{\mathrm{a}}$ & $2.02^{\mathrm{b}}$ & $2.33^{\mathrm{c}}$ & $2.39^{\mathrm{c}}$ & 0.09 & $<0.001$ \\
\hline & 우 & $0.42^{\mathrm{a}}$ & $1.33^{\mathrm{b}}$ & $1.45^{\mathrm{b}}$ & $1.85^{\mathrm{c}}$ & $1.88^{\mathrm{c}}$ & 0.12 & $<0.001$ \\
\hline Feed $\left(10^{-2}\right)$ & $\hat{0}$ & $5.89^{\mathrm{a}}$ & $41.15^{\mathrm{b}}$ & $89.53^{\mathrm{c}}$ & $47.39^{\mathrm{d}}$ & $49.96^{\mathrm{e}}$ & 6.10 & $<0.001$ \\
\hline
\end{tabular}

a, b, c, d, e Values within a row with different superscripts differ significantly a $P<0.01$.

Further study found that with the increase of age, average daily gain gradually decreased (Figure 4C), the daily demand for virtual water gradually increased, Increasing the same weight requires more and more virtual water. For goats, the growth of $1 \mathrm{~kg}$ mutton requires a virtual water content about $0.136 \mathrm{~m}^{3}$ at 40 days of age, requiring a virtual water content about $0.893 \mathrm{~m}^{3}$ at 6 months, requiring a virtual water content about $2.708 \mathrm{~m}^{3}$ at 12 months of age, requiring a virtual Water content about $8.567 \mathrm{~m}^{3}$ at 24 days of age, the required virtual water content about $17.875 \mathrm{~m}^{3}$ at 36 months of age (Figure 4D). The same estimation method that was used above for goats was used for sheep, the growth of $1 \mathrm{~kg}$ mutton requires a virtual water content about $0.391 \mathrm{~m}^{3}$ at 40 days of age, requiring a virtual water content about $3.200 \mathrm{~m}^{3}$ at 6 months,
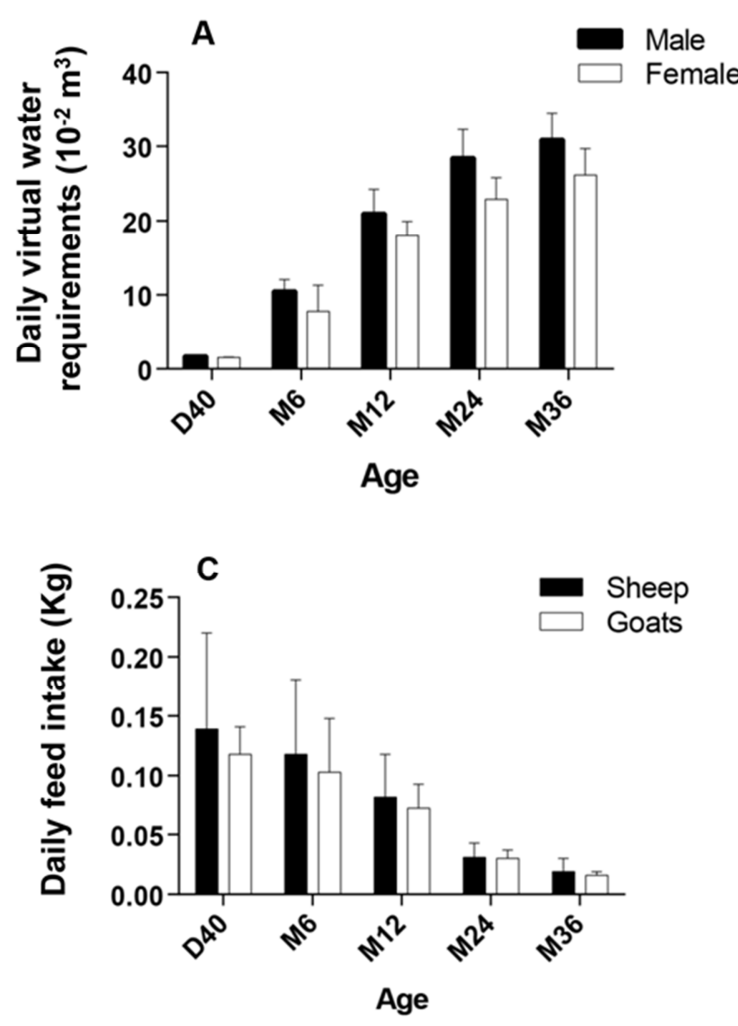

requiring a virtual water content about $10.433 \mathrm{~m}^{3}$ at 12 months of age, requiring a virtual Water content about 15.161 $\mathrm{m}^{3}$ at 24 days of age, the required virtual water content about $48.442 \mathrm{~m}^{3}$ at 36 months of age (Figure 4D). Further analysis found that daily gain consumption gradually decreased with age while the virtual water demand gradually increased (Figure 4D); additionally, as animal weight increased, more virtual water was also needed. Taking the actual purpose of feeding and other circumstances into account, the optimal time for slaughter would be when the sheep and goats meet the requirements of marketing time. To improve water resources productivity, water consumption should be reduced.
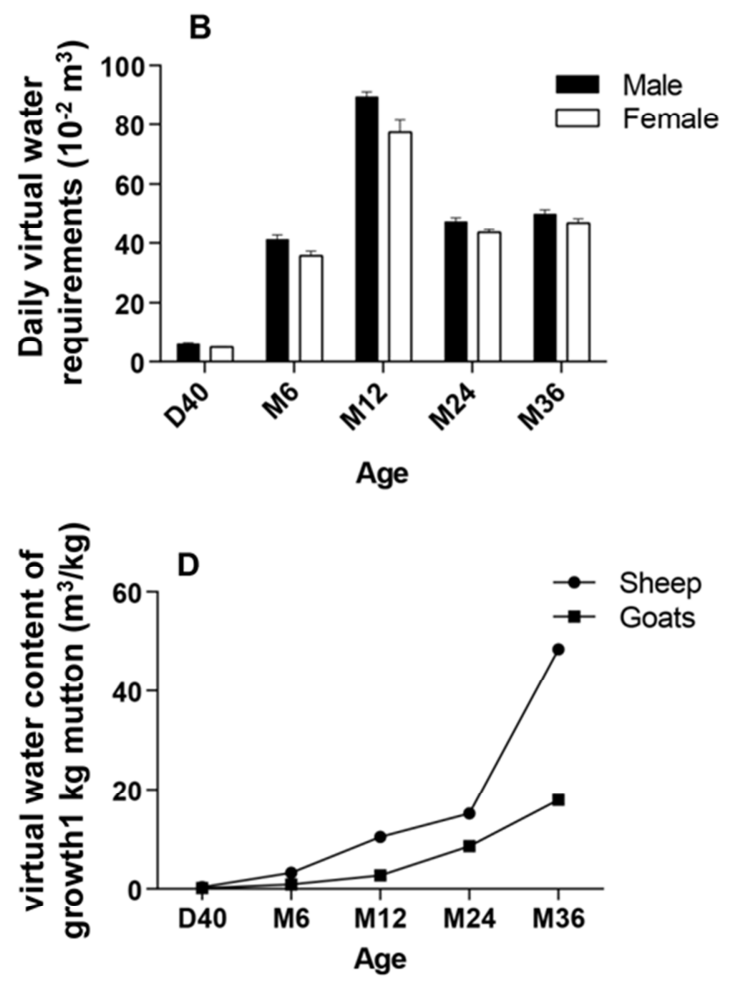

Figure 4. Daily intake and virtual water requirements for sheep and goats. (A) Daily virtual water requirements for goats $\left(10^{-2} \mathrm{~m}^{3}\right)$. (B) Daily virtual water requirements for sheep $\left(10^{-2} \mathrm{~m}^{3}\right)$. (C) Daily feed intake for sheep and goats ( $\left.\mathrm{kg}\right)$. (D) The growth of $1 \mathrm{~kg}$ mutton requires a virtual water content at different age group for sheep and goats $\left(\mathrm{m}^{3} / \mathrm{kg}\right)$. 


\subsection{Relevant Factors Influencing the Difference in Virtual Water Demand}

Upon further analysis of increasing age and feed intake, the dietary virtual water demand also exhibited a gradual increase in general. The virtual water demand was determined by two dietary aspects: daily feed intake and the virtual water content of the feed per unit weight. These varied based on the proportion of the feed material in the feed, the feed intake, and the virtual water requirement per unit weight. The fastest phase of growth and development for sheep and goats occurs between 40 days to 6 months, followed by 6 months to 12 months, 12 to 24 months, and 24 to 36 months of age. After 36 months of age, the body weight of sheep and goats remains relatively stable. In order to maintain growth and development and supply the nutritional feed intake needs, the virtual water demand and daily intake exhibited the same increasing trends.

\section{Discussion}

\subsection{Virtual Water Content for Sheep and Goats}

Based on data provided by the FAO and the World Trade Organization (WTO), sheep consume an estimated $5948 \mathrm{~m}^{3}$ $/ t$ of water in China [13]. The results of this experiment were much higher than those estimates, and this may be due to the following points: (1) Baseline data for the paper study were collected from international organizations and the WTO [13]. Data for this study was based on actual local production and incomes in different Provinces. Because Ningxia and Shaanxi experience serious water shortages in China, feed water consumption is higher than the average national level; (2) they estimated the average water content for Chinese sheep [13], while this study calculated the virtual water content of North China sheep. These differences in sheep variety, feed ingredients, feed intake, and water consumption lead to different virtual water content; (3) Previous studies based their analysis on China's farming per capita income conditions on the condition of grazing [13], and this paper studied large-scale livestock breeding; (4) According to previous study [13], the feeding process was divided into underage and adult and the feeding cycle was longer, while this study divided animals into different growth stages: the supplemental period, weaning period, adolescence, breeding period, and adult period. Because of the different nutritional needs at different stages and different feed material, we found that there were large differences in the feed virtual water content at different stages. Therefore, the results obtained in the present study are rather in line with actual water content values. This study can provide a reference for related research.

\subsection{Effects of Breeding Water Consumption on Regional Water Resources}

Global meat production has almost doubled in the period
1980-2004 and this upward trend will continue given the projected doubling of meat production in the period 2000-2050 [14, 15]. According to FAO regulations, under the premise of guaranteeing water resources security, water consumption is $2.7 \mathrm{~m}^{3}$ per person per day in the world (FAO 2008). The average daily water consumption for an adult goat is $0.28 \mathrm{~m}^{3}$. In 2014, the water consumption of Shaanxi reached $7.12 \times 10^{8} \mathrm{~m}^{3}$ for the goat breed, accounting for $7.1 \%$ of the residential annual water consumption and $9.47 \%$ of the agricultural water consumption. The average water content was $5234 \mathrm{~m}^{3} / \mathrm{t}$. These results showed that the virtual water content of goats was $4825.3 \mathrm{~m}^{3} / \mathrm{t}$, which was lower than the global average [13], but the low degree of modernization in China's sheep and goat industry also adds to water consumption and waste.

With the improvement of the national economy, China's citizens are consuming more cashmere fiber and mutton products. Consumers favor the quality of Cashmere fiber and meat and the demand for goat is increasing. In order to improve residents' incomes, China has issued a series of policies that support the breeding of goats. In this positive environment, the amount of goat breeding has increased year by year, nearly doubling in 2015 compared to 2012 . Goat not only provide local lamb and cashmere products, but are also exported to other provinces and cities through trade [16]. It can be seen from the results of this experiment that sheep farming requires significant water resources. If goat products are exported to other regions, the provinces water resources are also transferred, exacerbating the shortage of water resources in arid areas.

In summary, sheep breeding has a greater impact on China's regional water resources than goat breeding. Willie suggested that an increase in animal product consumption would lead to a significant depletion of local water resources [17]. Previous researchers argued that a significant increase in livestock products would put enormous pressure on water resources [18]. Previous researcher found that livestock production is currently over-exploiting existing water resources, according to research into livestock production chains $[19,20]$. These findings are consistent with the results from this experiment. Crop-animal production systems have a profound impact on regional water resources.

\section{Conclusion}

This study found that water consumption of sheep and goats was different at different ages, and water consumption also increased with age. Virtual water demand is made up of the virtual water requirement, water consumption, and service water, while the virtual water requirement of the feed alone makes up more than $99 \%$ of that total. Therefore, the virtual water requirement of feed is the main factor of influence for total the virtual water requirement. Feed intake and feed water demand have a direct impact on virtual water demand. Regional water resources are determined by the herd structure and quantity of breeding age adults as well as the individual virtual water 
demand, and the breeding water consumption of different ages and sexes has an important influence on regional water resources. In summary, age, sex, the virtual water content of feed ingredients, the raw material type of the feed and its proportion in the feed, regional culture, age structure, and quantity were the main factors of influence for the virtual water demand of sheep and goats. Local government policies can be implemented to replace feed type and reduce the use of high water consumption feed raw materials, promote drip irrigation technology, adjust the farming structure, and reduce the number of breeding sheep and goats. Crop import trade strategies can be used to increase the import of high water-consuming crops, instead of the virtual water consumption of the sheep and goat industry output, thereby alleviating the pressure on local water resources.

\section{Acknowledgements}

This work was supported by China Agriculture Research System (CARS-39), and Grants-in Project "Special Fund for Agro-scientific Research in the Public Interest (201303059)".

\section{Author Contributions}

All authors listed, have made substantial, direct and intellectual contribution to the work, and approved it for publication.

\section{Conflict of Interests}

The authors declare that they have no conflict of interests.

\section{Appendix}

Table A1. Daily ration formula and nutrient levels of Goat.

\begin{tabular}{ll}
\hline Ingredients & Composition\% \\
\hline Corn grain & 25.6 \\
Soybean oil & 4 \\
Soybean meal & 2 \\
Wheat bran & 5.6 \\
Rice straw & 10 \\
Alfalfa & 20 \\
$\mathrm{CaCO}_{3}$ & 0.6 \\
$\mathrm{CaHCO}_{3}$ & 0.7 \\
$\mathrm{NaCl}$ & 0.5 \\
Premix & 1 \\
Total & 100 \\
\hline
\end{tabular}

The premix provides the following per kg of diet: VA 7500 IU, VD 1050 IU, VE $10 \mathrm{IU}, \mathrm{Fe} 5500 \mathrm{mg}$, Cu $500 \mathrm{mg}$, Mn $5000 \mathrm{mg}$, Zn $4000 \mathrm{mg}$, Se 32.5 $\mathrm{mg}$, I $100 \mathrm{mg}$, Co $32.5 \mathrm{mg}$

Table A2. Daily ration formula and nutrient levels of Sheep.

\begin{tabular}{|c|c|c|c|c|c|}
\hline Ingredients (\%) & 36months & 24months & 12months & 6months & 40days \\
\hline Corn grain & 35.89 & 35.89 & 27.24 & 34.53 & 34.53 \\
\hline Soybean oil & 0.50 & 0.50 & 0 & 0.50 & 0.50 \\
\hline Soybean meal & 4.84 & 4.84 & 12.76 & 6.90 & 6.90 \\
\hline Sunflower cake & 0 & 0 & 0 & 3.08 & 3.08 \\
\hline Millet straw & 0 & 0 & 49 & 0 & 0 \\
\hline Rice straw & 0 & 0 & 6 & 0 & 0 \\
\hline Alfalfa & 53.77 & 53.77 & 0 & 50 & 50 \\
\hline Premix (5\%) & 5 & 5 & 5 & 5 & 5 \\
\hline Total & 100 & 100 & 100 & 100 & 100 \\
\hline \multicolumn{6}{|l|}{ Nutrient levels (\%) } \\
\hline DM & 88.69 & 88.69 & 89.49 & 88.28 & 88.28 \\
\hline $\mathrm{DE} \mathrm{MJ} / \mathrm{kg}$ & 10.21 & 10.21 & 9.10 & 10.19 & 10.19 \\
\hline $\mathrm{CP}$ & 12.75 & 12.75 & 10.34 & 12.73 & 12.73 \\
\hline $\mathrm{EE}$ & 2.52 & 2.52 & 1.91 & 2.55 & 2.55 \\
\hline $\mathrm{CF}$ & 24.11 & 24.11 & 18.52 & 23.19 & 23.19 \\
\hline Ash & 4.89 & 4.89 & 5.92 & 4.85 & 4.85 \\
\hline $\mathrm{Ca}$ & 1.54 & 1.54 & 0.90 & 1.51 & 1.51 \\
\hline$P$ & 0.49 & 0.49 & 0.31 & 0.51 & 0.51 \\
\hline
\end{tabular}

The premix provides the following per kg of diet: $\mathrm{FeSO}_{4} \cdot 7 \mathrm{H}_{2} \mathrm{O} 170 \mathrm{~g}, \mathrm{CuSO}_{4} \cdot 5 \mathrm{H}_{2} \mathrm{O} 70 \mathrm{~g}, \mathrm{MnSO}_{4} \cdot \mathrm{H}_{2} \mathrm{O} 203 \mathrm{~g}, \mathrm{ZnSO}_{4} \cdot 7 \mathrm{H}_{2} \mathrm{O} 240 \mathrm{~g}, \mathrm{CoCl}_{2} \cdot 6 \mathrm{H}_{2} \mathrm{O} 510 \mathrm{mg}$, $\mathrm{Na}_{2} \mathrm{SeO}_{3} 130 \mathrm{mg}$, KI $220 \mathrm{mg}$, carrier $278.1 \mathrm{~g}$, VA $30000 \mathrm{KIU}$, VD $37800 \mathrm{KIU}$, VE $30 \mathrm{KIU}$.

\section{References}

[1] Gleeson, T., et al., Water balance of global aquifers revealed by groundwater footprint. Nature, 2012. 488 (7410): p. 197-200.

[2] Wang, X., et al., Shortage of water resources in China and countermeasures. Water Pollut Control, 2014. 7: p. 1-5.

[3] Allan, J., Fortunately there are substitutes for water otherwise our hydro-political futures would be impossible. Priorities for water resources allocation and management, 1993. 13: p. 26.

[4] Allan, J., Overall perspectives on countries and regions. Rogers, P. and Lydon, P. Water in the Arab World: perspectives and prognoses, Harvard University Press, Cambridge, Massachusetts, 1994: p. 65-100.

[5] Allan, J. A., Virtual water-the water, food, and trade nexus. Useful concept or misleading metaphor? Water international, 2003. 28 (1): p. 106-113. 
[6] Zhao, C. and B. Chen, Driving force analysis of the agricultural water footprint in China based on the LMDI method. Environmental science \& technology, 2014. 48 (21): p. 12723-12731.

[7] Shtulltrauring, E. and N. Bernstein, Virtual water flows and water-footprint of agricultural crop production, import and export: A case study for Israel. Science of the Total Environment, 2018. 622: p. 1438-1447.

[8] Silva, V. D. P. R. D., et al., Virtual water and water self-sufficiency in agricultural and livestock products in Brazil. Journal of Environmental Management, 2016. 184 (Pt 2): p. 465-472.

[9] Zhang, Y., et al., Virtual water flows in the international trade of agricultural products of China. Science of the Total Environment, 2016. 557-558: p. 1-11.

[10] Allan, J. A. and T. Allan, The Middle East water question: Hydropolitics and the global economy. Vol. 2. 2002: Ib Tauris.

[11] Oki, T., et al. Virtual water trade to Japan and in the world. in Hoekstra, AY 'Virtual water trade: Proceedings of the International Expert Meeting on Virtual Water Trade', Value of Water Research Report Series. 2003.

[12] Chapagain, A. K. and A. Y. Hoekstra, Virtual water flows between nations in relation to trade in livestock and livestock products. 2003, UNESCO-IHE Delft, The Netherlands.

[13] Chapagain, A. and A. Hoekstra. Virtual water trade: A quantification of virtual water flows between nations in relation to international trade of livestock and livestock products. in
Virtual water trade. Proceedings of the international expert meeting on virtual water trade. 2003. UNESCO-IHE (United Nations Educational, Scientific and Cultural Organization-Institute for Water Education), Delft, The Netherlands.

[14] Steinfeld, H., et al., Livestock's long shadow: environmental issues and options. 2006: Food \& Agriculture Org.

[15] Mekonnen, M. M. and A. Y. Hoekstra, A global assessment of the water footprint of farm animal products. Ecosystems, 2012. 15 (3): p. 401-415.

[16] Qi, Y., et al., Genetic diversity and relationships of 10 Chinese goat breeds in the Middle and Western China. Small Ruminant Research, 2009. 82 (2): p. 88-93.

[17] Wilhite, D. A., A methodology for drought preparedness. Natural Hazards, 1996. 13 (3): p. 229-252.

[18] Descheemaeker, K., T. Amede, and A. Haileslassie, Improving water productivity in mixed crop-livestock farming systems of sub-Saharan Africa. Agricultural water management, 2010. 97 (5): p. 579-586.

[19] Rockström, J. and J. Barron, Water productivity in rainfed systems: overview of challenges and analysis of opportunities in water scarcity prone savannahs. Irrigation Science, 2007. 25 (3): p. 299-311.

[20] Pelletier, N. and P. Tyedmers, Forecasting potential global environmental costs of livestock production 2000-2050. Proceedings of the National Academy of Sciences, 2010. 107 (43): p. 18371-18374. 